\title{
Monitoring Sexually Transmitted Infections in Cervicovaginal Exfoliative Samples in Mexican Women
}

\author{
Fabiola Hernández-Rosas ${ }^{1} \mathbb{D}$, Manuel Rey-Barrera ${ }^{2}$, Ulises Conejo-Saucedo ${ }^{3}$, Erika Orozco-Hernández ${ }^{3}$, \\ Liliana Maza-Sánchez ${ }^{3}$, Enrique Navarro-Vidal ${ }^{3}$, Yasmín López-Vera ${ }^{4}$, María del Carmen Ascencio-Gordillo ${ }^{4}$ \\ and Mercedes Piedad de León-Bautista ${ }^{3,5, *}$
}

check for

updates

Citation: Hernández-Rosas, F.;

Rey-Barrera, M.; Conejo-Saucedo, U.;

Orozco-Hernández, E.;

Maza-Sánchez, L.; Navarro-Vidal, E.; López-Vera, Y.; Ascencio-Gordillo, M.d.C.; de León-Bautista, M.P. Monitoring Sexually Transmitted Infections in Cervicovaginal Exfoliative Samples in Mexican Women. Pathogens 2021, 10, 1618. https://doi.org/10.3390/ pathogens 10121618

Academic Editors:

Antonella Marangoni and Claudio Foschi

Received: 31 October 2021 Accepted: 30 November 2021 Published: 13 December 2021

Publisher's Note: MDPI stays neutral with regard to jurisdictional claims in published maps and institutional affiliations.

Copyright: (c) 2021 by the authors. Licensee MDPI, Basel, Switzerland. This article is an open access article distributed under the terms and conditions of the Creative Commons Attribution (CC BY) license (https:// creativecommons.org/licenses/by/ $4.0 /)$.
1 Biomedical Engineering Faculty, Anáhuac University, El Marques 76246, Mexico; fhernandezrosas85@gmail.com

2 Cambrico Biotech, 41015 Sevilla, Spain; mrey@cambri.co

3 Translational Medicine, Vanguard and Technology Transfer Sector, Human Health Department, Central ADN Laboratories, Morelia 58341, Mexico; conejet@me.com (U.C.-S.); eorozco@centraladn.com (E.O.-H.); lilianamaza@yahoo.com.mx (L.M.-S.); enrique.navarro@centraladn.com (E.N.-V.)

4 Hospital de la Mujer de la Secretaría de Salud de Michoacán, Morelia 58295, Mexico; lopezvyas@yahoo.com.mx (Y.L.-V.); m.ag62@hotmail.com (M.d.C.A.-G.)

5 Escuela de Medicina, Universidad Vasco de Quiroga, Morelia 58090, Mexico

* Correspondence: mercedespiedad@hotmail.com

Abstract: Background. Globally, Sexually Transmitted Infections (STIs) are a major cause of morbidity in sexually active individuals, having complications in reproduction health and quality of life. In concordance with the Sustainable Development Goals (SDG), the study aimed to investigate the prevalence of Candida spp., Ureaplasma spp., Trichomonas vaginalis, Neisseria gonorrhoeae, Chlamydia trachomatis, HSV, and Mycoplasma spp. from cervicovaginal samples and to correlate them with the gynecological history of the patients. Methods. Our analytical, prospective, and cross-sectional study included 377 women who participated in a reproductive health campaign during 2015-2016. Anthropometric and gynecological variables were obtained. Cervicovaginal specimens were collected and analyzed with a multiplex in-house PCR to detect Candida spp., Ureaplasma spp., Trichomonas vaginalis, Neisseria gonorrhoeae, HSV, Mycoplasma spp., and Chlamydia trachomatis. Results. The positive cases were $175 / 377(46.4 \%)$ to at least one of the microorganisms. The most frequent pathogen detected in this population was Ureaplasma spp. $(n=111,29.4 \%)$, followed by Mycoplasma spp. $(n=56$, $14.9 \%$ ) and Candida spp. ( $n=47,12.5 \%) ; 33.7 \%$ of the positive cases were single infections, whereas $12.7 \%$ had coinfection. The multiplex PCR assay was designed targeting nucleotide sequences. Conclusions. Our data demonstrated that monitoring STIs among asymptomatic patients will encourage target programs to be more precisely and effectively implemented, as well as make these programs more affordable, to benefit society by decreasing the prevalence of STIs.

Keywords: sexually transmitted infection; PCR multiplex detection; sustainable development goals

\section{Introduction}

Sexually Transmitted Infections (STIs) and Bacterial Vaginosis (BV) represent a concerning important health problem throughout the world. Globally, the most common STIs are caused by Chlamydia trachomatis (CT), Neisseria gonorrhoeae (NG), and Trichomonas vaginalis (TV) [1,2]. In some cases, these infections are asymptomatic, masking the pathogen leading to fertility complications and consequences in sexual and maternal-fetal health. Moreover, the proinflammatory microenvironment caused by these pathogens increases the risk of acquiring other infections such as HIV [3].

The STI epidemic is dynamic; thus, for gathering robust data, these diseases and infections need to be monitored to allow target programs to be more precisely and effectively implemented to benefit society. On this concerning fact, to improve the sexual health of 
men and women, the Sustainable Development Goals (SDG) were postulated with the clear objective to radically reduce the prevalence of STIs and deaths caused by these infections [4]. As part of these strategies, we are encouraged to improve the screening methods and to make them more widely available to the population, as current molecular assays only offer solutions with high costs of the commercial kits [5], the usage of sophisticated platforms [6,7] and expensive shipping costs. Therefore, based on its global targets, the ultimate objective pursued with this project is the development of a diagnostic kit for STI and BV that will allow establishing the specific causal infectious agents with a single assay. Nevertheless, to achieve this goal, one of the particular objectives was to describe the prevalence of STI and BV in asymptomatic women. Therefore, in this study, we showed the correlation of gynecological history with the prevalence of Candida spp., Ureaplasma spp., Trichomonas vaginalis, Neisseria gonorrhoeae, Chlamydia trachomatis, HSV, and Mycoplasma spp. from cervicovaginal samples, though a multiplex in-house PCR which has a potential clinical utility.

\section{Materials and Methods}

\subsection{Study Subjects and Selection Criteria}

An analytical, prospective, and cross-sectional study was conducted with 377 women from the state of Michoacán, located in central Mexico. They accepted to participate in the screening campaign to detect Candida spp., Ureaplasma spp., Trichomonas vaginalis, Neisseria gonorrhoeae, Chlamydia trachomatis, HSV, and Mycoplasma spp. during the period from December 2014 to June 2015. All the women were aged 15 to 65 years old and were apparently healthy and asymptomatic at the time of sample collection. The anthropometric information and gynecological history were obtained from a standardized individual questionnaire.

\subsection{Ethical Statement}

The study was approved by the medical and ethical research committee at Hospital de la Mujer de la Secretaría de Salud de Michoacán, with project number 090. The protocols were carried out according to the Declaration of Helsinki and the current health laws in Mexico. The informed consent was signed by all the participants before performing any clinical procedure.

\subsection{Specimen Collection}

All clinical cervicovaginal exfoliative samples were obtained by scraping the epithelium with a nylon cytobrush (Puritan Medical Products, Guilford, ME, USA). Every specimen was stored in Universal Transport Medium (Copan Diagnostics, Murrieta, CA, USA) at room temperature and processed in the molecular diagnostic laboratory Central ADN in Morelia, Michoacán, Mexico.

\subsection{DNA Extraction}

The extraction of the total DNA was carried out by using Instagene Matrix (Bio-Rad, Hercules, CA, USA), following the manufacturer's instructions. Briefly, $200 \mu \mathrm{L}$ of the sample was transferred to $200 \mu \mathrm{L}$ tubes. Then, the samples were centrifuged at 14,000 rpm for $1 \mathrm{~min}$. The pellet was washed twice with PBS-Tween 20. Finally, $50 \mu \mathrm{L}$ of Instagene Matrix was added to the pellet and incubated at $56^{\circ} \mathrm{C}$ for $30 \mathrm{~min}$. The sample was boiled to $100{ }^{\circ} \mathrm{C}$ for $8 \mathrm{~min}$. The supernatants were stored at $-20^{\circ} \mathrm{C}$ until their use.

\subsection{Primer Design}

The DNA sequences of Candida spp., Ureaplasma spp., Trichomonas vaginalis, Neisseria gonorrhoeae, HSV, and Mycoplasma spp. were obtained from GenBank (accession numbers listed in Table 1). Every gene-specific primer pair was designed as a multiplex PCR assay with non-dimerizing primer set combinations by using the MPprimer software [8]. The primer sequences for the PCR assay of bacterial, parasites, and viral pathogens are 
described in Supplementary Table S1. For the detection of Chlamydia trachomatis, we used a pair of primers previously reported [9].

Table 1. GenBank accession numbers to design the multiplex PCR assay.

\begin{tabular}{|c|c|c|c|c|}
\hline Pathogen & Gene & Amplicon Size & Gene Bank Access & Reference \\
\hline Mycoplasma spp. & 16S rRNA & 184 & $\begin{array}{c}\text { AY466443.1 } \\
\text { MN149400.1 }\end{array}$ & In-house \\
\hline Ureaplasma spp. & 16S rRNA & 397 & EU932691.1 & \multirow{2}{*}{ In-house } \\
\hline Candida spp. & 18S rRNA & 473 & X53497.1 & \\
\hline Chlamydia trachomatis & $\mathrm{CP}$ & 241 & СР054431.1 & [9] \\
\hline Neisseria gonhorroeae & pJD1 (cppb) & 278 & AP018387.1 & In-house \\
\hline Trichomonas vaginalis & 18S rRNA & 310 & KX061409.1 & In-house \\
\hline Human Herpes Virus & DNA POL & 205 & $\begin{array}{l}\text { MH697529.1 } \\
\text { MH697449.1 }\end{array}$ & In-house \\
\hline
\end{tabular}

16S rRNA, 16S ribosomal RNA; 18S rRNA, 18S ribosomal RNA CP; Chlamydia trachomatis plasmid; pJD1 (cppb); Cryptic plasmid protein B; DNA POL, DNA polymerase.

\subsection{Positive Control Strains, Sequence Analysis, and Standardization}

As positive controls, well-characterized clinical samples of the cervix of Candida spp., Ureaplasma spp., Trichomonas vaginalis, Neisseria gonorrhoeae, Chlamydia trachomatis, HSV, and Mycoplasma spp. were kindly shared by Hospital de la Mujer de la Secretaría de Salud de Michoacán. Single PCR was performed using well-characterized clinical samples to assure specificity. Thus, to confirm the results, the amplified products were purified and sequenced with forward and reverse primers at Macrogen (Seoul, Korea). The sequences were blasted against available fragments in the gene bank to identify the microorganism.

\subsection{Positive Control Constructs}

Once we confirmed the specificity of the primers, the specific DNA fragments were cloned into pGEM vector to generate the constructs pGEM/CA, pGEM/UP, pGEM/TV, $\mathrm{pGEM} / \mathrm{NG}, \mathrm{pGEM} / \mathrm{CT}$, pGEM/HSV, and $\mathrm{pGEM} / \mathrm{MY}$ as positive synthetic controls. The plasmids were introduced into E. coli $D H-5 \alpha$ and purified using alkaline lysis [10]. The inserts were verified by a PCR reaction and confirmed by automated sequencing analysis at Macrogen (Seoul, Korea), using the forward and reverse probes to the corresponding pathogen. The sequences were blasted in the gene bank to identify the microorganism.

\subsection{PCR Assays Conditions}

The single PCR reactions were carried out using QIAGEN ${ }^{\circledR}$ Multiplex PCR Kit (206145, Qiagen, Hilden, Germany), in a final volume of $10 \mu \mathrm{L}$ prepared with PCR master mix buffer $[1 \times]$ f, and $2 \mu \mathrm{L},(\sim 100 \mathrm{ng} / \mu \mathrm{L})$ of total nucleic acid extraction. Due to the variability of the Tm of primers, and to increase the specificity, we performed a touch-down PCR with a Hot Start activation step at $95{ }^{\circ} \mathrm{C}$ for $5 \mathrm{~min}$; followed by 35-cycle steps, consisting of denaturation step at $95{ }^{\circ} \mathrm{C}$ for $1 \mathrm{~min}$, after, the first 16 cycles at $65^{\circ} \mathrm{C}$ for $1 \mathrm{~min}$; for the next 19 cycles, the annealing temperature decreased $0.3^{\circ} \mathrm{C}$ each. The extension step was at $72{ }^{\circ} \mathrm{C}$ for $45 \mathrm{~s}$. The PCR steps were carried out using a standard Veriti ${ }^{\mathrm{TM}}$ Thermal Cycler (LS4375786, Thermo Fisher Scientific, Waltham, MA, USA).

To resolute the PCR, the total reaction mixture was subjected to electrophoresis on a $2.5 \%$ agarose gel dyed with Red Safe (21141, iNtRON, Seongnam, Korea). The bands were visualized on a UV transilluminator and photographed (ENDURO ${ }^{\text {TM }}$ GDS, LabNet international, Edison, NJ, USA).

Once the single-target PCR system was successful, we performed an in-house multiplex PCR assay with the confirmed probe sets to detect Candida spp., Ureaplasma spp., Trichomonas vaginalis, Neisseria gonorrhoeae, Chlamydia trachomatis, HSV, and Mycoplasma spp. 
Human Actin primers were used as an internal control, $5^{\prime}$ ACCGAGCGCGGCTACAG3' and $5^{\prime}$ CTTAATGTCACGCACGATTTCC $3^{\prime}$ (ShineGene Molecular Biotech) forward and reverse, respectively.

To reinforce the results with the multiplex assay, the detected amplicons were purified to perform an automated sequencing analysis at Macrogen (Seoul, Korea), using the specific probes to the corresponding pathogen, forward and reverse, respectively. The sequences were blasted in the gene bank to identify the microorganism.

\subsection{Statistical Analysis}

Statistical analyses were performed using SPSS version 25.0 (IBM Statistics, Armonk, NY, USA). Descriptive analyses of categorical variables were expressed as frequency and percentages such as age group, gynecological history, and STI results. The quantitative continuous variables were expressed as means \pm standard deviation. Pearson chi-square test $\left(\mathrm{Chi}^{2}\right)$ was used to assess relationships between variables and the STI using a significance level of $p<0.05$ (two-tailed). The conditional logistic regression was used to estimate odds ratios (OR) of factors associated with positive multiplex PCR results with $95 \%$ confidence intervals (CI). The multivariate logistic regression included the effects of age and clinical variables.

\section{Results}

\subsection{Multiplex PCR Assay}

Based on the target species, the designed primers were specific to detect Candida spp., Ureaplasma spp., Trichomonas vaginalis, Neisseria gonorrhoeae, HSV, Mycoplasma spp. and Chlamydia trachomatis. The multiplex PCR assay was performed using a touch-down PCR assay (Figure 1). All the well-characterized clinical samples were correctly identified, and to demonstrate the standardization, we performed the experiments in triplicates, indicating a high degree of reproducibility of this multiplex assay. It is relevant that in some cases, the well-characterized clinical samples presented an unidentified amplicon, due to the donated clinical samples being tested with single-target PCR to detect just one pathogen. Thus, to solve this incognito, unknown bands, $397 \mathrm{bp}$ (Figure 1, line 4, 8) and $308 \mathrm{bp}$ amplicon (Figure 1, line 8) were automated sequenced with forward and reverse primers at Macrogen (Seoul, Korea). The reattributed sequences were blasted [11] against available fragments in the gene bank to identify the microorganism. The results matched with Ureaplasma and Trichomonas vaginalis, both pathogens included in our test. These sequencing results showed that our method identified more than one pathogen in the same sample. These results demonstrate the standardization parameters of our assay. Further experiments must be performed to complete the validity of the test.

\subsection{Clinical Findings}

A total of 377 cervical samples from women aged 15 to 65 years old were analyzed. The gynecological history of the patients is detailed in Table 2. The average age of the population of the study was $37.7 \pm 11.8$ years. Most of the patients were in the age group 15 to 20 years $(64.2 \%)$ and 21 to 25 years $(20.2 \%)$. Of all patients, $34.5 \%$ had multiple sexual partners and $6.1 \%$ had their first sexual intercourse before 15 years old. A history of previous STI was found in $11.4 \%$ of the patients. The gynecological examination revealed that most of the patients had a normal cervix (41.7\%), and only $11.7 \%$ had a cervical lesion (Table 2). The most frequent abnormality was an abnormal vaginal discharge (15.9\%). Of all of the patients, $50.9 \%$ had at least one contraceptive method. Smoking habit was described in $15.9 \%$ of the study population. Only 15 patients underwent cervical cytology, the results are shown in Table 2. 


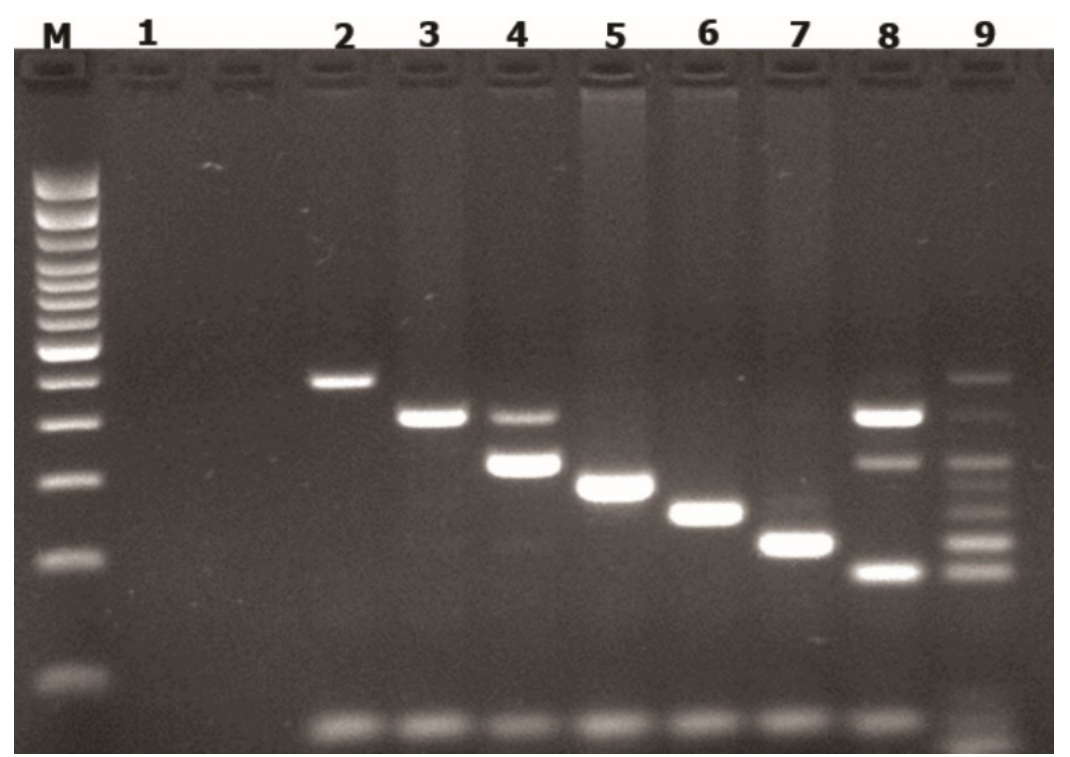

Figure 1. Multiplex End-point PCR. Gel electrophoresis (2.5\% agarose) of PCR products from well-characterized samples to detect Candida spp., Ureaplasma spp., Trichomonas vaginalis, Neisseria gonorrhoeae, Chlamydia trachomatis, HSV and Mycoplasma spp. M, Ladder 100 bp marker (Invitrogen, Waltham, MA, USA); (1) negative control (molecular grade water); (2-8) well-characterized samples: (2) Candida spp. (473 bp), (3) Ureaplasma spp. (397 bp) and Trichomonas vaginalis (308 bp); (4) Trichomonas vaginalis (308 bp); (5) Neisseria gonorrhoeae (278 bp); (6) Chlamydia trachomatis (241 bp); (7) HSV (205 bp); (8) Mycoplasma spp. (184 bp), Ureaplasma spp. (397 bp) and Trichomonas vaginalis (308 bp); (9) pool of cloning plasmids as a positive control. The band of $\sim 65 \mathrm{bp}$ corresponds to actin beta as an internal control.

Table 2. Gynecological history $(n=377)$.

\begin{tabular}{ccc}
\hline Sexual History & $n$ & $\%$ \\
\hline Multiple sexual partners & 130 & 34.5 \\
\hline AFSI $<$ 15 years & 23 & 6.1 \\
\hline Age group & & 64.2 \\
\hline 15-20 years & 242 & 20.2 \\
\hline $20-25$ years & 76 & 8.0 \\
\hline $25-30$ years & 30 & 1.6 \\
\hline$>30$ years & 6 & 11.4 \\
\hline Infection & & \\
\hline History of STI & 43 & 0.0 \\
\hline Gynecologic-obstetric history & & 9.5 \\
\hline Puerperio & 0 & 4.5 \\
\hline Postmenopause & 36 & 2.1 \\
\hline Contraception & 17 & 0.5 \\
\hline Oral contraception & 8 & \\
\hline Injectable contraceptives & 2 & \\
\hline Subdermal Implant & & \\
\hline
\end{tabular}


Table 2. Cont.

\begin{tabular}{|c|c|c|}
\hline Sexual History & $n$ & $\%$ \\
\hline IUD & 12 & 3.2 \\
\hline Hysterectomy & 18 & 4.8 \\
\hline $\mathrm{BTL} / \mathrm{BPS}$ & 135 & 35.8 \\
\hline \multicolumn{3}{|l|}{ Gynecological examination } \\
\hline Normal cervix & 158 & 41.9 \\
\hline Abnormal cervix & 3 & 0.8 \\
\hline Cervix lesion & 43 & 11.4 \\
\hline Cervicitis & 12 & 3.2 \\
\hline Increase in vaginal discharge & 60 & 15.9 \\
\hline Intermenstrual bleeding & 2 & 0.5 \\
\hline Cervical and vaginal discharge & 8 & 2.1 \\
\hline Cervicitis and vaginal discharge & 23 & 6.1 \\
\hline Inflammatory changes & 68 & 18 \\
\hline \multicolumn{3}{|l|}{ Health maintenance } \\
\hline Tobacco & 60 & 15.9 \\
\hline \multicolumn{3}{|l|}{ Cervical cytology } \\
\hline Without PAP & 362 & 96.0 \\
\hline LSIL + HPV & 6 & 1.6 \\
\hline LSIL + HPV + CIN1 & 8 & 2.1 \\
\hline $\mathrm{LSIL}+\mathrm{CIN} 2$ & 1 & 0.3 \\
\hline
\end{tabular}

AFSI, Age at First Sexual Intercourse; STI, Sexually Transmitted Infections; BTL/BPS, bilateral tubal ligation, or bilateral partial salpingectomy; IUD, intrauterine device; PAP, Papanicolaou test; HPV, Human Papillomavirus; LSIL, low-grade squamous intraepithelial lesion; CIN, Cervical Intraepithelial Neoplasia.

\subsection{Detection of STI in Cervical Samples Using Multiplex PCR Assay}

The multiplex PCR panel allowed the identification of Candida spp. (473 bp), Ureaplasma spp. (397 bp), Trichomonas vaginalis (310 bp), Neisseria gonorrhoeae (278 bp), Chlamydia trachomatis (241 bp), HSV (205 bp), and Mycoplasma spp. (184 bp) (Figure 1). As part of the quality control and assurance of our multiplex test and having internal consistency, a random selection of positive samples to different pathogens was automated sequenced, demonstrating a 100\% of concordance with the genes detected in GeneBank. The positive cases were $175 / 377(46.4 \%)$ to at least one of the microorganisms included in the test. The most frequent pathogen detected in this population was Ureaplasma spp. $(n=111$, $29.4 \%)$, followed by Mycoplasma spp. ( $(n=56,14.9 \%)$, Candida spp. $(n=47,12.5 \%)$, Chlamydia trachomatis (4.2\%), and Trichomonas vaginalis (1.1\%) (Figure 2a). We did not find positive samples for N. gonorrhoeae or HSV. Of the positive cases, 33.7\% were single infections, whereas $12.7 \%$ had coinfection with other pathogens, mostly: Candida albicans/Ureaplasma spp. (4.5\%), Ureaplasma spp./Mycoplasma spp. (3.4\%), and Ureaplasma spp./Chlamydia trachomatis $(2.1 \%)$. Of all samples, $53.6 \%$ were negative (Figure $2 \mathrm{~b}$ ). 
a)

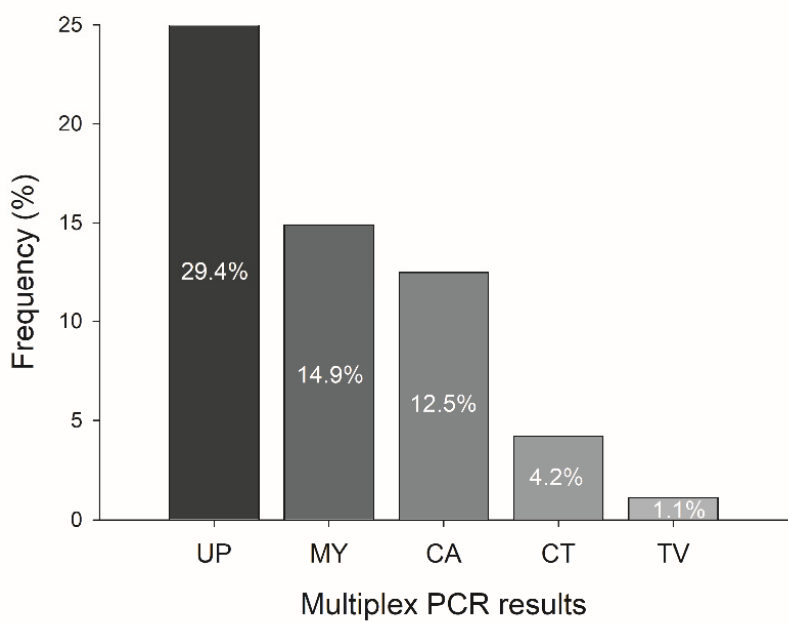

b)

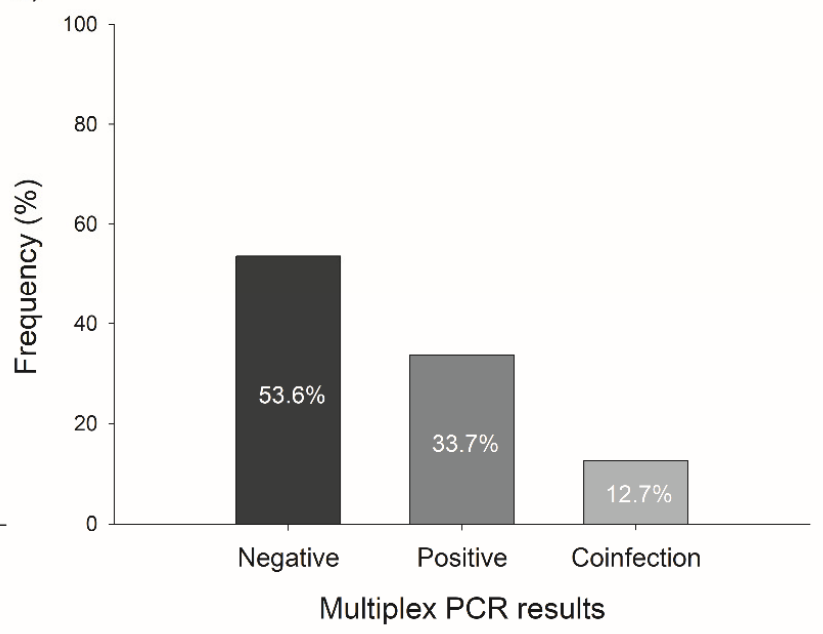

Figure 2. Results of multiplex PCR by pathogens. (a) Pathogens detected by multiplex PCR. (b) Frequency of positive and coinfection results. Abbreviations: UP, Ureaplasma spp.; MY, Mycoplasma spp.; CA, Candida spp.; CT, Chlamydia trachomatis; TV, Trichomonas vaginalis.

The samples with positive results were stratified according to age group (Figure 3). We found the highest frequency of Ureaplasma spp., Mycoplasma spp., and Trichomonas vaginalis at the 21 to 30 and 41 to 50 years age group. Nevertheless, in the 31 to 40 years age group the frequency of Candida spp. was higher (Figure 3). Chlamydia trachomatis frequency was common at the age of 21 to 30 years (Figure 3 ).

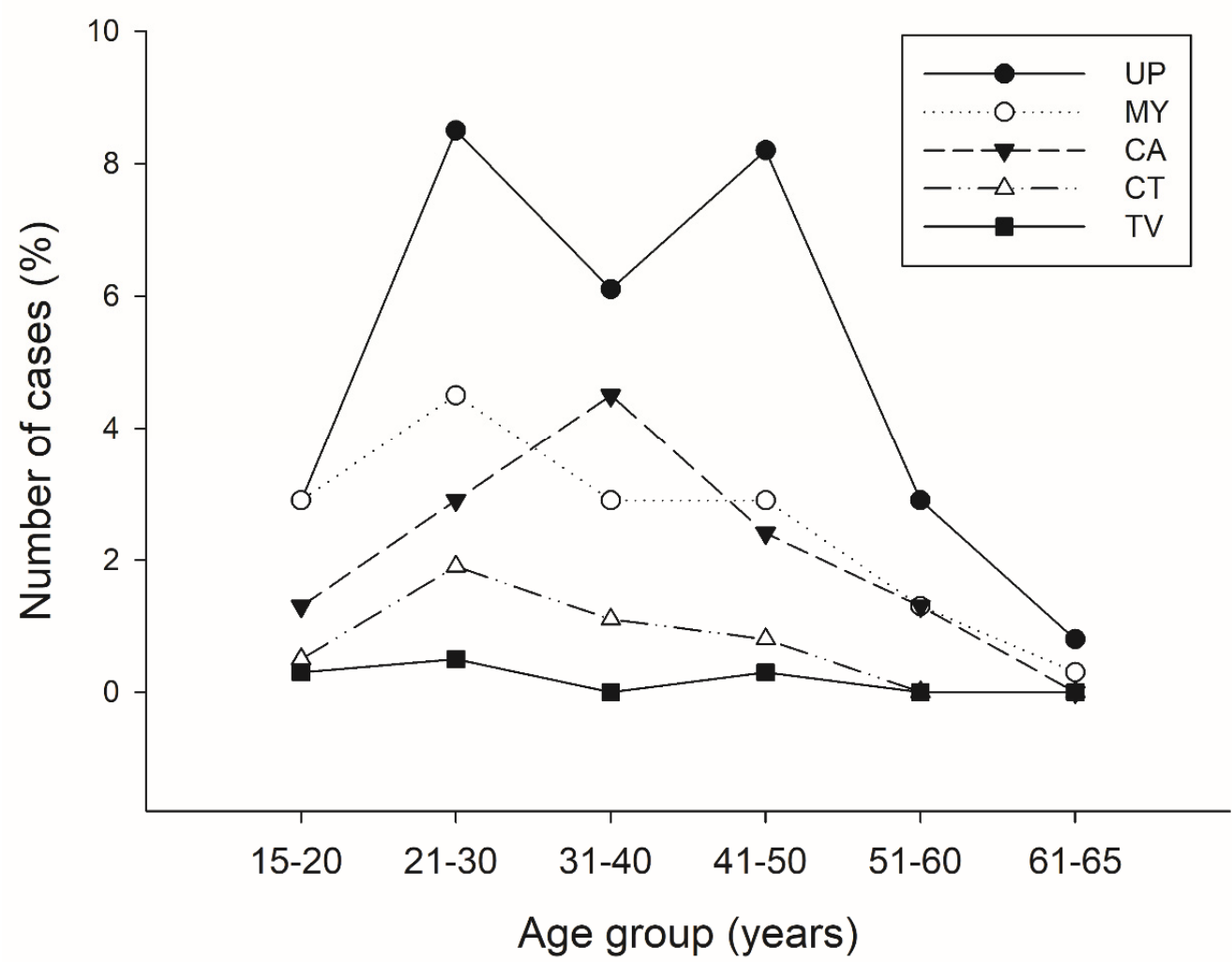

Figure 3. Pathogens detected by multiplex PCR stratified by age 15-20, 21-30, 31-40, 41-50, 51-60, 6165 years. Abbreviations: UP, Ureaplasma spp.; MY, Mycoplasma spp.; CA, Candida spp.; CT, Chlamydia trachomatis; TV, Trichomonas vaginalis. 
We compared two different age groups, less than 30 years and above 30 years, with the multiplex PCR results (Figure 4). The most frequent microorganisms detected were Candida spp., Ureaplasma spp., Mycoplasma spp., and Chlamydia trachomatis in women older than 30 years. In the case of coinfection, the positive results were more frequent in women younger than 30 years of age (Figure 4 ).

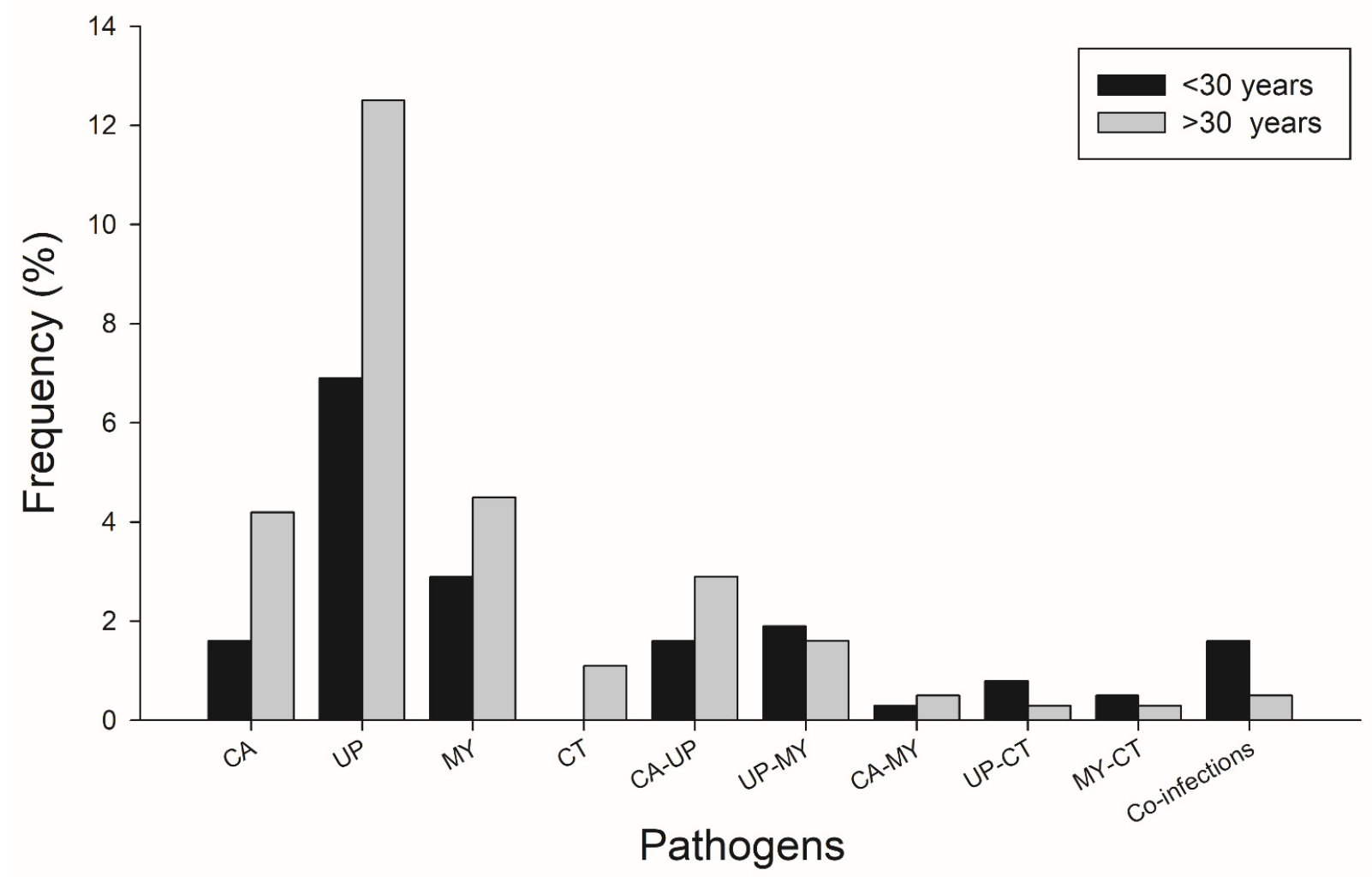

Figure 4. Age-Stratified Multiplex PCR Results. Abbreviations: UP, Ureaplasma spp.; MY, Mycoplasma spp.; CA, Candida spp.; CT, Chlamydia trachomatis; TV, Trichomonas vaginalis.

Most of the patients with a positive result were asymptomatic. However, during the pelvic examination, the most significant signs and symptoms were cervicitis, abnormal vaginal discharge, and inflammatory changes in the cervix (Table 3). The last was the most frequent macroscopic found in samples positive to Ureaplasma spp. and Mycoplasma spp.; $5.8 \%$ and $3.8 \%$, respectively, followed by an increased vaginal discharge, with $1.6 \%$ and $2.1 \%$, respectively (Table 3 ). Comparing symptomatic or asymptomatic patients concerning the presence of any pathogen, we did not find significant differences between the two groups $(p>0.05)$ (Table 3). Due to the absence of N. gonorrhoeae and HSV positive samples, we could not correlate this information with the pelvic examination.

Table 3. Frequency of Ureaplasma spp., Mycoplasma spp., Candida spp., and Chlamydia trachomatis in symptomatic and asymptomatic patients.

\begin{tabular}{|c|c|c|c|c|c|c|c|c|c|c|c|c|}
\hline \multirow[b]{2}{*}{$\begin{array}{l}\text { Signs and } \\
\text { Symptoms }\end{array}$} & \multicolumn{3}{|c|}{ Ureaplasma spp. } & \multicolumn{3}{|c|}{ Mycoplasma spp. } & \multicolumn{3}{|c|}{ Candida spp. } & \multicolumn{3}{|c|}{ Chlamydia trachomatis } \\
\hline & $n \overline{(\%)}$ & $\begin{array}{c}+ \\
n(\%)\end{array}$ & $\begin{array}{c}p \\
\text { value }\end{array}$ & $n \overline{(\%)}$ & $\stackrel{+}{n}+\frac{(\%)}{}$ & $\begin{array}{c}p \\
\text { value }\end{array}$ & $n \overline{(\%)}$ & $\begin{array}{c}+ \\
n \stackrel{(\%)}{\%}\end{array}$ & $\begin{array}{c}p \\
\text { value }\end{array}$ & $n \overline{(\%)}$ & $\begin{array}{c}+ \\
n \stackrel{\%}{\%})\end{array}$ & $\begin{array}{c}p \\
\text { value }\end{array}$ \\
\hline Asymptomatic & $182(48.3)$ & $79(21.0)$ & 0.351 & $228(60.5)$ & $33(8.8)$ & 0.193 & $229(60.7)$ & $32(8.5)$ & 0.552 & $249(66.0)$ & $12(3.2)$ & 0.789 \\
\hline Cervicitis & $8(2.1)$ & $4(1.1)$ & 0.125 & $11(2.9)$ & $1(0.3)$ & 0.172 & $11(2.9)$ & $1(0.3)$ & 0.412 & $12(3.2)$ & $0(0.0)$ & 0.305 \\
\hline $\begin{array}{l}\text { Vaginal } \\
\text { discharge }\end{array}$ & $30(8.0)$ & $6(1.6)$ & 0.087 & $28(7.4)$ & $8(2.1)$ & 0.120 & $29(7.7)$ & $7(1.9)$ & 0.286 & $34(9.0)$ & $2(0.5)$ & 0.176 \\
\hline $\begin{array}{l}\text { Inflammatory } \\
\text { changes }\end{array}$ & $46(12.2)$ & $22(5.8)$ & 0.064 & $54(14.3)$ & $14(3.7)$ & 0.071 & $61(16.2)$ & $7(1.9)$ & 0.078 & $66(17.5)$ & $2(0.5)$ & 0.081 \\
\hline
\end{tabular}


Furthermore, we analyzed the potential risk factors associated with the presence of at least one of the microorganisms tested in the multiplex panel. A univariate logistic regression model for sexual behavior and an adjusted multivariate model for age and clinical variables were explored. We found that having multiple sexual partners represents a risk factor for a positive diagnostic test in the study population $(\mathrm{OR}=1.205 ; 95 \% \mathrm{CI}=1.016-1.454$; $p=0.043$ ) (Table 4). According to the Pap smear results and the multiplex PCR test, two patients with LSIL + HPV and one patient who had LSIL + HPV + CIN1 were positive to Mycoplasma spp. (data not shown).

Table 4. Risk factors for positive PCR results $(n=377)$.

\begin{tabular}{|c|c|c|c|c|c|c|}
\hline Variable & PCR Negative & PCR Positive & OR $(95 \% \mathrm{CI})$ & $p$-value & OR $(95 \% \text { CI })^{ \pm}$ & $p$-Value ${ }^{ \pm}$ \\
\hline \multicolumn{7}{|c|}{ AFSI $<15$ years } \\
\hline No & $194(51.5)$ & $160(42.4)$ & Ref. & & - & \\
\hline Yes & $8(2.1)$ & $15(4.0)$ & $2.273(0.940-5.499)$ & 0.062 & $2.055(0.839-5.037)$ & 0.115 \\
\hline \multicolumn{7}{|c|}{ History of STI } \\
\hline No & $176(46.7)$ & 158 (41.9) & Ref. & & & \\
\hline Yes & $26(6.9)$ & $17(4.5)$ & $1.373(0.718-2.625)$ & 0.336 & $1.303(0.683-2.488)$ & 0.422 \\
\hline \multicolumn{7}{|c|}{ MSP } \\
\hline No & 142 (37.7) & 105 (27.9) & Ref. & & & \\
\hline Yes & $60(15.9)$ & $70(18.6)$ & $1.267(1.021-1.571)$ & 0.036 & $1.205(1.016-1.454)$ & 0.043 \\
\hline \multicolumn{7}{|c|}{ Tobacco habit } \\
\hline No & $173(45.9)$ & $144(38.2)$ & Ref. & & & \\
\hline Yes & $29(7.7)$ & $31(8.2)$ & $0.779(0.448-1.353)$ & 0.374 & $0.848(0.483-1.490)$ & 0.567 \\
\hline
\end{tabular}

AFSI, age of first sexual intercourse; MSP, multiple sexual partners; STI, Sexually Transmitted Infections; OR, odds ratios; CI, confidence intervals. $\mathrm{Chi}^{2}$ test was used to compare between groups. A $p$-value $<0.5$ was considered significant. \pm ORs and $p$-values adjusted for age and clinical variables. Ref; Reference of the logistic regression models formed to identify independent risk factors associated with positive PCR results.

Ultimately, we independently explored the risk factors associated with positive results considering the most frequent pathogens found in our study. Our results demonstrated that the age of first sexual intercourse before 15 years represents a risk factor for acquiring an infection by Ureaplasma spp. $(\mathrm{OR}=3.184 ; 95 \% \mathrm{CI}=1.338-7.574 ; p=0.009)$, meanwhile, above 15 years is a protective factor for Chlamydia trachomatis infection $(\mathrm{OR}=0.881$; $95 \% \mathrm{CI}=0.825-0.042)$. Moreover, we showed that multiple sexual partners represent a risk factor for Mycoplasma spp. infection. $(\mathrm{OR}=1.281 ; 95 \% \mathrm{CI}=1.050-1.321 ; p=0.042)$ (Table 5).

Table 5. Analysis of risk factors associated to multiplex PCR results $(n=377)$.

\begin{tabular}{|c|c|c|c|c|c|c|}
\hline Pathogen & $\begin{array}{c}\text { Yes } \\
n(\%)\end{array}$ & $\begin{array}{c}\text { No } \\
n(\%)\end{array}$ & OR (CI 95\%) & $p$-Value & OR $\left(\mathrm{CI}\right.$ 95\%) ${ }^{ \pm}$ & $p$-Value ${ }^{ \pm}$ \\
\hline \multicolumn{7}{|c|}{ ASFI < 15 years } \\
\hline UP & $13(3.4)$ & $98(26.0)$ & $3.396(1.442-7.998)$ & 0.003 & $3.184(1.338-7.574)$ & 0.009 \\
\hline MY & $5(1.3)$ & $51(13.5)$ & $1.650(0.587-4.642)$ & 0.338 & $1.343(0.455-3.963)$ & 0.593 \\
\hline CA & $3(0.8)$ & $44(11.7)$ & $1.057(0.302-3.703)$ & 0.931 & $1.049(0.306-3.594)$ & 0.939 \\
\hline $\mathrm{CT}$ & $0(0.0)$ & $16(4.2)$ & $0.936(0.911-0.962)$ & 0.297 & $0.881(0.825-0.042)$ & 0.337 \\
\hline \multicolumn{7}{|c|}{ History of STI } \\
\hline UP & $12(3.2)$ & $99(26.3)$ & $1.088(0.537-2.206)$ & 0.814 & $1.048(0.517-2.126)$ & 0.897 \\
\hline MY & $5(1.3)$ & $51(13.5)$ & $1.370(0.515-3.645)$ & 0.527 & $1.243(0.460-3.362)$ & 0.668 \\
\hline
\end{tabular}


Table 5. Cont.

\begin{tabular}{|c|c|c|c|c|c|c|}
\hline Pathogen & $\begin{array}{c}\text { Yes } \\
n(\%)\end{array}$ & $\begin{array}{c}\text { No } \\
n(\%)\end{array}$ & OR (CI 95\%) & $p$-Value & OR (CI 95\%) \pm & $p$-Value ${ }^{ \pm}$ \\
\hline CA & $3(0.8)$ & $44(11.7)$ & $2.023(0.600-6.820)$ & 0.247 & $2.037(0.599-6.924)$ & 0.254 \\
\hline $\mathrm{CT}$ & $3(0.8)$ & $13(3.4)$ & $0.540(0.148-1.977)$ & 0.345 & $0.465(0.124-1.743)$ & 0.256 \\
\hline \multicolumn{7}{|c|}{ Multiple sexual partners } \\
\hline UP & $43(11.4)$ & $68(18.0)$ & $0.769(0.485-1.217)$ & 0.261 & $0.811(0.506-1.300)$ & 0.385 \\
\hline MY & $27(7.2)$ & $29(7.7)$ & $1.311(1.107-1.707)$ & 0.019 & $1.281(1.105-1.321)$ & 0.042 \\
\hline CA & $18(4.8)$ & $29(7.7)$ & $0.828(0.441-1.555)$ & 0.556 & $0.820(0.427-1.575)$ & 0.551 \\
\hline $\mathrm{CT}$ & $8(2.1)$ & $8(2.1)$ & $0.510(0.187-1.393)$ & 0.182 & $0.602(0.211-1.718)$ & 0.343 \\
\hline \multicolumn{7}{|c|}{ Tobacco habit } \\
\hline UP & $14(3.7)$ & $97(25.7)$ & $1.449(0.761-2.759)$ & 0.257 & $1.580(0.818-3.055)$ & 0.173 \\
\hline MY & $18(4.8)$ & $38(10.1)$ & $0.485(0.195-1.205)$ & 0.082 & $0.261(0.103-1.365)$ & 0.094 \\
\hline CA & $5(1.3)$ & $42(11.1)$ & $1.680(0.636-4.438)$ & 0.291 & $1.693(0.640-4.482)$ & 0.289 \\
\hline $\mathrm{CT}$ & $6(1.6)$ & $10(2.7)$ & $0.293(0.102-0.840)$ & 0.016 & $0.349(0.119-1.025)$ & 0.055 \\
\hline
\end{tabular}

AFSI, age of first sexual intercourse; MSP, multiple sexual partners; STI, Sexually Transmitted Infections; OR, odds ratios; CI, confidence intervals. $\mathrm{Chi}^{2}$ test was used to compare between groups. A $p$-value $<0.5$ was considered significant. \pm ORs and $p$-values adjusted for age and clinical variables.

\section{Discussion}

The Sustainable Development Goals (SDG) were postulated to reduce STIs and deaths caused by these infections, to improve the sexual health of men and women [4]. Therefore, our social commitment is motivated by the socialization of technologies, to make them achievable for all the social sectors. In this sense, STIs are highly prevalent pathologies in our country and other regions, particularly affecting poor women strata. This social context presents severe clinical outcomes since a high percentage are asymptomatic [12], there is a lack of information $[13,14]$ to differentiate pathological from physiological situations, and there is an absence of medical check-ups and affordable screening strategies. All these causes can result in complications such as pelvic inflammatory disease (PID), which can cause infertility or ectopic pregnancy, complications derived from the Chlamydia trachomatis and Neisseria gonorrhoeae infection; nevertheless, more than $70 \%$ of the cases have an unknown etiology. Many studies have found different pathogens that cause non-gonococcal or non-chlamydial symptoms. Other pathogens involved are Mollicutes such as Ureaplasma urealyticum and Ureaplasma paroum. All of these are correlated with PID and infertility, as well as urethritis in men [15].

The WHO Global Strategy of the Health Sector on STIs 2016-2021 estimated 357 million new cases per year worldwide among people aged 15 to 49 years. The prevalence of some viral STIs is equally high, with an estimated 417 million people infected [16]. The prevalence of these STIs varies by region and gender. These epidemics have a profound impact on the health and lives of children, adolescents, and adults around the world, causing fetal and neonatal deaths, infertility, and higher risk of HIV, among other health problems.

Our study showed an overall rate of STI-positive cases (46.4\%), higher in women aged 41-50 years, a frequent percentage described in a diversity of populations [17-19]. In this sense, Kim et al. demonstrated rates of STI-positive status of $49.2 \%$ and showed a peak distribution in those 40-49 years old, which highlights comparable results with our study population [19].

Here, we identify the most prevalent pathogens: Ureaplasma spp., Mycoplasma spp., Candida spp., and Chlamydia trachomatis. The prevalence of Ureaplasma spp. and Mycoplasma spp. in sexually active female populations from various regions ranged from 12 to $64 \%$ and 1 to $16 \%$, respectively [20]. In a similar study realized by Kim et al., Ureaplasma spp. was the most common STI in Korean women, with an overall prevalence 
of $32.5 \%$, of which $50 \%$ were under the age of 30 [10]. Compared with our study, the prevalence of Ureaplasma spp. was minor (29.4\%); in contrast, we found that most of the positive cases of Ureaplasma spp. appeared in women older than 30 years. The reports concerning the prevalence of these pathogens are heterogeneous among populations.

On the other hand, the prevalence of Chlamydia trachomatis in our study was $4.2 \%$, similar to a recent epidemiological Mexican study realized with 2352 women of Central Mexico, which reported an estimated prevalence of $4.3 \%$ of this pathogen [21]. It is well described that Chlamydia trachomatis is one of the most relevant pathogens impacting global health. Here, the data demonstrated a similar prevalence shown in Latin America [22]. This fact reveals the importance of epidemiological surveillance at the regional level. According to SDG, the prevalence and incidence must decrease in the coming years; therefore, affordable screening tests should be implemented or improved. Moreover, the highest STI prevalence occurs mainly between 15 to 24 years old, and we reiterated this information. During late adolescence age, it is common to have frequent sexual [23] contact with many sexual partners, increasing the risk of acquiring any STI. Here we found that having sexual intercourse after 15 years old is a protective factor to avoid Chlamydia trachomatis infection; on the contrary, this factor becomes dangerous when the individual has precocious sexual onset. Indeed, STI screening methods are one of the most important efforts to improve by 2030 [4], but also educational campaigns to strengthen the global hits in SDG should be applied.

Regarding Trichomonas vaginalis, the prevalence in our study was $1.1 \%$. Trichomoniasis is a notable disease in Mexico; however, epidemiological data reported by the Health Societies do not represent the real magnitude of these STIs because there is no total coverage of public health services and because many women are asymptomatic [24]. In addition, there is scarce information available in Mexico about the prevalence of Trichomonas vaginalis, which is limited to local studies conducted in a few cities in Mexico. In this respect, a Mexican report encouraged to determine the frequency of nine sexually transmitted pathogens, coinfections, and risk factors in patients attending obstetrics and gynecology clinics in Jalisco, in western Mexico. The results showed a higher prevalence of $14.2 \%$ compared with our results [25].

While the prevalence of T. vaginalis in Latin America is around 11-15\% [26], the CDC estimated a minor prevalence of $T$. vaginalis of $1.6 \%$ in USA women [27]. These data show a marked variability and regionalization of $T$. vaginalis transmission among countries.

Coinfections were not the most prevalent cases, with $12.7 \%$, with similar results $(12.8 \%)$ in Cervical Cytology of Samples using homolog PCR techniques [17]. Another common finding was the coinfections: Candida spp. with Ureaplasma spp. and Mycoplasma spp., followed by Chlamydia trachomatis with Ureaplasma spp. and Mycoplasma spp. in patients younger than 30 years old. Similar results were reported in patients with urogenital infections [28]. Even though the microorganisms belonging to the genus Ureaplasma and Mycoplasma are not part of the normal urogenital microbiota, they spread through sexual contact and are associated with chronic non-gonococcal urethritis (NGU) and preterm delivery. Hence, detecting asymptomatic patients is mandatory because of the sexual health and maternal-fetal implications [29]. There is controversy because the asymptomatic carriage of these bacteria is regular, and the majority of individuals will not develop signs or symptoms. Thus, this type of screening test for women should be analyzed to avoid antimicrobial resistance. Furthermore, we should continue performing extensive analyses to solve issues regarding bacterial load and symptoms [30].

Candida spp. is a microorganism that is part of the commensal microbiota, and it is related to vulvovaginal candidiasis (CVV), a clinical condition characterized by an infection of the genital, vulvar and vaginal mucosa. The disease is a consequence of factors that allow the excessive proliferation of yeast [31]. Although this pathology is not classified as an STI, it is a condition that favors the acquisition of another infection. In our study, this microorganism was the third most prevalent pathogen, and associated with coinfection with Chlamydia trachomatis and Mycoplasma and Ureaplasma. This coinfection 
was described previously $[17,28]$. Due to that Candida spp. was detected in coinfection with these pathogens, the main key questions are formulated. This yeast inhibits growths or the virulence of other pathogens, perhaps providing chemical resources for bacterial survival in the microenvironment, or promoting microorganism dissemination [32]. Our report has some limitations since we designed the panel test with no specific detection of Candida species. Thus, a supplementary test needs to be carried out to differentiate species of Candida.

Our study was focused on clinically healthy women with asymptomatic infection, a risk group with consequences in reproductive and maternal-fetal health, but also a higher risk of acquiring other types of infections such as HIV (human immunodeficiency virus) [33-35]. The use of NAATs is considered the gold standard tests to detect Chlamydia trachomatis and Neisseria gonorrhoeae; they are recommended by the CDC because of their high specificity and sensitivity when we compared them to traditional techniques [29,36]. Hence, our panel described the most prevalent STIs such as Chlamydia trachomatis (CT), Candida spp., Ureaplasma spp., Mycoplasma spp., and Trichomonas vaginalis (TV).

In summary, it is necessary not only to encourage the capacity of laboratories but also to design and introduce affordable STI diagnostics and sexual educational campaigns, for different uses such as detecting high-risk groups, monitoring treatment, surveillance studies, quality assurance of laboratory tests, and research. Finally, we emphasized that monitoring STIs among asymptomatic patients will encourage the implementation of target programs more precisely and effectively, as well as make these programs more affordable to benefit society and decrease the prevalence of STIs.

Supplementary Materials: The following are available online at https:/ /www.mdpi.com/article/10 .3390/pathogens10121618/s1. Supplementary Table S1: Primers sequences.

Author Contributions: Conceived and designed the experiments: M.R.-B. and M.P.d.L.-B.; Sample collection: Y.L.-V. and M.d.C.A.-G.; Performed the experiments: L.M.-S., E.N.-V., M.P.d.L.-B., U.C.-S. and E.O.-H.; Formal analysis: M.P.d.L.-B. and F.H.-R.; Software: M.R.-B., M.P.d.L.-B. and F.H.-R.; Writing—original draft: M.P.d.L.-B. and F.H.-R.; Writing—review and editing: M.P.d.L.-B., F.H.-R. and M.R.-B. All authors have read and agreed to the published version of the manuscript.

Funding: This work was supported by Programa de Estímulos a la Innovación funded by the CONACyT under the identifier project number 232475.

Institutional Review Board Statement: The study was approved by the medical and ethical research committee at Hospital de la Mujer de la Secretaría de Salud de Michoacán, with project number 090. All protocols were performed according to the guidelines of the Declaration of Helsinki and the current health laws in Mexico.

Informed Consent Statement: The informed consent was signed by all the participants before performing any clinical procedure.

Data Availability Statement: Not applicable.

Acknowledgments: We want to thank all of the participants for donating the samples, as well as the medical staff's support at Hospital de la Mujer de la Secretaría de Salud de Michoacán to achieve this project. Furthermore, we thank Susmith González Franco, Mariana García González, Chem. Flavio Hernández Barajas, and Biol. Claudia Rangel Soto, for their administrative support.

Conflicts of Interest: The authors declared no potential conflict of interest concerning the research, authorship, and/or publication of this article.

\section{References}

1. Unemo, M.; Bradshaw, C.S.; Hocking, J.S.; de Vries, H.J.C.; Francis, S.C.; Mabey, D.; Marrazzo, J.M.; Sonder, G.J.B.; Schwebke, J.R.; Hoornenborg, E.; et al. Sexually transmitted infections: Challenges ahead. Lancet Infect. Dis. 2017, 17, e235-e279. [CrossRef]

2. Rowley, J.; Vander Hoorn, S.; Korenromp, E.; Low, N.; Unemo, M.; Abu-Raddad, L.J.; Chico, R.M.; Smolak, A.; Newman, L.; Gottlieb, S.; et al. Chlamydia, gonorrhoea, trichomoniasis and syphilis: Global prevalence and incidence estimates, 2016. Bull. World Health Organ. 2019, 97, 548-562. [CrossRef] [PubMed] 
3. Katusiime, C.; Schlech, W.F., 3rd; Parkes-Ratanshi, R.; Sempa, J.; Kambugu, A. Characteristics of Sexually Transmitted Infections among High-Risk HIV-Positive Patients Attending an Urban Clinic in Uganda. J. Int. Assoc. Provid. AIDS Care 2016, $15,36-41$. [CrossRef]

4. Chersich, M.F.; Delany-Moretlwe, S.; Martin, G.; Rees, H. Advancing STI priorities in the SDG era: Priorities for action. Global Health 2018, 14, 6. [CrossRef]

5. De Salazar, A.; Espadafor, B.; Fuentes-Lopez, A.; Barrientos-Duran, A.; Salvador, L.; Alvarez, M.; Garcia, F. Comparison between Aptima Assays (Hologic) and the Allplex STI Essential Assay (Seegene) for the diagnosis of Sexually transmitted infections. PLoS ONE 2019, 14, e0222439. [CrossRef]

6. Xiu, L.; Zhang, C.; Li, Y.; Wang, F.; Peng, J. Simultaneous detection of eleven sexually transmitted agents using multiplexed PCR coupled with MALDI-TOF analysis. Infect. Drug Resist. 2019, 12, 2671-2682. [CrossRef]

7. Parcell, B.J.; Ratnayake, L.; Kaminski, G.; Olver, W.J.; Yirrell, D.L. Value of repeat testing using Cepheid GeneXpert CT/NG for indeterminate PCR results when diagnosing Chlamydia trachomatis and Neisseria gonorrhoeae. Int. J. STD AIDS 2015, $26,65-67$. [CrossRef]

8. Shen, Z.; Qu, W.; Wang, W.; Lu, Y.; Wu, Y.; Li, Z.; Hang, X.; Wang, X.; Zhao, D.; Zhang, C. MPprimer: A program for reliable multiplex PCR primer design. BMC Bioinf. 2010, 11, 143. [CrossRef] [PubMed]

9. Mahony, J.B.; Luinstra, K.E.; Sellors, J.W.; Chernesky, M.A. Comparison of plasmid- and chromosome-based polymerase chain reaction assays for detecting Chlamydia trachomatis nucleic acids. J. Clin. Microbiol. 1993, 31, 1753-1758. [CrossRef]

10. Maniatis, T.; Fritsch, E.F.; Sambrook, J. Molecular Cloning: A Laboratory Manual; Cold Spring Harbor Laboratory: Cold Spring Harbor, NY, USA, 1982; p. 545.

11. Morgulis, A.; Coulouris, G.; Raytselis, Y.; Madden, T.L.; Agarwala, R.; Schaffer, A.A. Database indexing for production MegaBLAST searches. Bioinformatics 2008, 24, 1757-1764. [CrossRef]

12. Orozco-Hoyos, N.; Baena, A.; Montoya-Ruiz, C.; Sanchez, G.I.; Restrepo, E. Prevalence of Chlamydia trachomatis in an asymptomatic female population attending cervical cytology services of three healthcare centers in Medellin, Colombia. Biomedica 2020, 40, 534-545. [CrossRef]

13. Paganella, M.P.; da Motta, L.R.; Adami, A.G.; Sperhacke, R.D.; Kato, S.K.; Pereira, G.F.M. Knowledge about sexually transmitted infections among young men presenting to the Brazilian Army, 2016: A STROBE-compliant national survey-based cross-sectional observational study. Medicine 2021, 100, e26060. [CrossRef]

14. Khan, M.A.; Rahman, M.; Khanam, P.A.; Barkate, K.; Kane, T.T.; Ashraf, A. Awareness of sexually transmitted disease among women and service providers in rural Bangladesh. Int. J. STD AIDS 1997, 8, 688-696. [CrossRef] [PubMed]

15. Haggerty, C.L.; Totten, P.A.; Tang, G.; Astete, S.G.; Ferris, M.J.; Norori, J.; Bass, D.C.; Martin, D.H.; Taylor, B.D.; Ness, R.B. Identification of novel microbes associated with pelvic inflammatory disease and infertility. Sex. Transm. Infect. 2016, 92, 441-446. [CrossRef] [PubMed]

16. Korenromp, E.L.; Wi, T.; Resch, S.; Stover, J.; Broutet, N. Costing of National STI Program Implementation for the Global STI Control Strategy for the Health Sector, 2016-2021. PLoS ONE 2017, 12, e0170773. [CrossRef] [PubMed]

17. Carneiro, F.P.; Daros, A.C.; Daros, A.C.M.; de Castro, T.; de Vasconcelos Carneiro, M.; Fidelis, C.R.; Vilioni, M.V.; da Costa Matsunaga, M.E.; Sidou, J.M.O.; Chaves, M.; et al. Cervical Cytology of Samples with Ureaplasma urealyticum, Ureaplasma parvum, Chlamydia trachomatis, Trichomonas vaginalis, Mycoplasma hominis, and Neisseria gonorrhoeae Detected by Multiplex PCR. Biomed. Res. Int. 2020, 2020, 7045217. [CrossRef]

18. Guralp, O.; Bostanci, A.; Ozerkman Basaran, E.; Schild-Suhren, M.; Kaya, B. Evaluation of the prevalence of sexually transmitted bacterial pathogens in Northern Cyprus by nucleic acid amplification tests, and investigation of the relationship between these pathogens and cervicitis. Turk. J. Obstet. Gynecol. 2019, 16, 242-248. [CrossRef]

19. Kim, Y.; Kim, J.; Lee, K.A. Prevalence of sexually transmitted infections among healthy Korean women: Implications of multiplex PCR pathogen detection on antibiotic therapy. J. Infect. Chemother. 2014, 20, 74-76. [CrossRef]

20. Manavi, K. A review on infection with Chlamydia trachomatis. Best Pract. Res. Clin. Obstet. Gynaecol. 2006, $20,941-951$. [CrossRef] [PubMed]

21. Lopez-Hurtado, M.; Garcia-Romero, S.; Escobedo-Guerra, M.R.; Bustos-Lopez, D.; Guerra-Infante, F.M. Prevalence of genital Chlamydia trachomatis infection in women attending in the National Institute of Perinatology from Mexico City. Rev. Chil. Infectol. 2018, 35, 371-376. [CrossRef]

22. Huai, P.; Li, F.; Chu, T.; Liu, D.; Liu, J.; Zhang, F. Prevalence of genital Chlamydia trachomatis infection in the general population: A meta-analysis. BMC Infect. Dis. 2020, 20, 589. [CrossRef]

23. Boislard, M.A.; van de Bongardt, D.; Blais, M. Sexuality (and Lack Thereof) in Adolescence and Early Adulthood: A Review of the Literature. Behav. Sci. 2016, 6, 8. [CrossRef] [PubMed]

24. Muzny, C.A. Why Does Trichomonas vaginalis Continue to be a "Neglected" Sexually Transmitted Infection? Clin. Infect. Dis. 2018, 67, 218-220. [CrossRef] [PubMed]

25. Casillas-Vega, N.; Morfin-Otero, R.; Garcia, S.; Llaca-Diaz, J.; Rodriguez-Noriega, E.; Camacho-Ortiz, A.; Ayala-Castellanos Mde, L.; Mendoza-Olazaran, S.; Flores-Trevino, S.; Petersen-Morfin, S.; et al. Sexually transmitted pathogens, coinfections and risk factors in patients attending obstetrics and gynecology clinics in Jalisco, Mexico. Salud Publica Mex. 2016, 58, 437-445. [CrossRef] 
26. Soto, R.J.; Ghee, A.E.; Nunez, C.A.; Mayorga, R.; Tapia, K.A.; Astete, S.G.; Hughes, J.P.; Buffardi, A.L.; Holte, S.E.; Holmes, K.K.; et al. Sentinel surveillance of sexually transmitted infections/HIV and risk behaviors in vulnerable populations in 5 Central American countries. J. Acquir. Immune Defic. Syndr. 2007, 46, 101-111. [CrossRef]

27. Satterwhite, C.L.; Torrone, E.; Meites, E.; Dunne, E.F.; Mahajan, R.; Ocfemia, M.C.; Su, J.; Xu, F.; Weinstock, H. Sexually transmitted infections among US women and men: Prevalence and incidence estimates, 2008. Sex. Transm. Dis. 2013, 40, 187-193. [CrossRef] [PubMed]

28. Paira, D.A.; Molina, G.; Tissera, A.D.; Olivera, C.; Molina, R.I.; Motrich, R.D. Results from a large cross-sectional study assessing Chlamydia trachomatis, Ureaplasma spp. and Mycoplasma hominis urogenital infections in patients with primary infertility. Sci. Rep. 2021, 11, 13655. [CrossRef]

29. Frolund, M.; Bjornelius, E.; Lidbrink, P.; Ahrens, P.; Jensen, J.S. Comparison between culture and a multiplex quantitative real-time polymerase chain reaction assay detecting Ureaplasma urealyticum and U. parvum. PLoS ONE 2014, 9, e102743. [CrossRef]

30. Horner, P.; Donders, G.; Cusini, M.; Gomberg, M.; Jensen, J.S.; Unemo, M. Should we be testing for urogenital Mycoplasma hominis, Ureaplasma parvum and Ureaplasma urealyticum in men and women?-A position statement from the European STI Guidelines Editorial Board. J. Eur. Acad. Dermatol. Venereol. 2018, 32, 1845-1851. [CrossRef]

31. Brandolt, T.M.; Klafke, G.B.; Goncalves, C.V.; Bitencourt, L.R.; Martinez, A.M.; Mendes, J.F.; Meireles, M.C.; Xavier, M.O. Prevalence of Candida spp. in cervical-vaginal samples and the in vitro susceptibility of isolates. Braz. J. Microbiol. 2017, 48, 145-150. [CrossRef]

32. Kruppa, M.D.; Jacobs, J.; King-Hook, K.; Galloway, K.; Berry, A.; Kintner, J.; Whittimore, J.D.; Fritz, R.; Schoborg, R.V.; Hall, J.V. Binding of Elementary Bodies by the Opportunistic Fungal Pathogen Candida albicans or Soluble beta-Glucan, Laminarin, Inhibits Chlamydia trachomatis Infectivity. Front. Microbiol. 2018, 9, 3270. [CrossRef] [PubMed]

33. Abou Tayoun, A.N.; Burchard, P.R.; Caliendo, A.M.; Scherer, A.; Tsongalis, G.J. A multiplex PCR assay for the simultaneous detection of Chlamydia trachomatis, Neisseria gonorrhoeae, and Trichomonas vaginalis. Exp. Mol. Pathol. 2015, 98, 214-218. [CrossRef] [PubMed]

34. Al-Moushaly, A. Considerations on male infertility in genital infections with Chlamydia Trachomatis (CT). J. Med. Life 2013, 6, 283-286. [PubMed]

35. Gottlieb, S.L.; Newman, L.M.; Amin, A.; Temmerman, M.; Broutet, N. Sexually transmitted infections and women's sexual and reproductive health. Int. J. Gynaecol. Obstet. 2013, 123, 183-184. [CrossRef] [PubMed]

36. Meyer, T. Diagnostic Procedures to Detect Chlamydia trachomatis Infections. Microorganisms 2016, 4, 25. [CrossRef] [PubMed] 